\title{
Evaluation of the Influence of the Polymer-Filler Interaction on Compounds Based on Epoxidized Elastomeric Matrix and Precipitated Silica
}

\author{
Tatiana L. A. C. Rocha \\ Deutsches Institut für Kautschuktechnologie e.V. \\ Instituto de Química, UFRGS \\ Marly M. Jacobi, Dimitrios Samios \\ Instituto de Química, UFRGS \\ Robert H. Schuster \\ Deutsches Institut für Kautschuktechnologie e.V.
}

\begin{abstract}
The introduction of epoxy groups into the main chain of elastomers has emerged as a promising alternative, considering the monitoring of polymer-filler interaction leading to changes in the properties of vulcanizates. The epoxidation reaction (in situ) was chosen to modify elastomers, such as polybutadiene (BR) and copolymer of styrenebutadiene-rubber (SBR), because it is a simple, easily controlled reaction, even considering the small epoxidation degree. The modification degree of the polymeric chain was studied with FT-IR and ${ }^{1} \mathrm{H}-\mathrm{NMR}$. The shift of the Tg to high temperatures with the increase of the epoxy group in the polymer chain was monitored through differential scanning calorimetry (DSC). An analysis of the dynamic modulus of the material in relation to its dependence on the amplitude and temperature was carried out. The interaction between epoxidized elastomeric matrix and silica as filler was extremely improved, even in the presence of very low content of epoxy groups into the polymer chain.
\end{abstract}

Keywords: Epoxidation, SBR, polymer-filler interaction, dynamic properties, precipitated silica.

\section{Introduction}

The production of analogous polymers has been studied basically for two reasons: the most common is the change in the nature of the polymer, which can be reached by using chemical modification, as well as the graft of specific groups into the polymer chain. The yield of modification can vary from very small quantities until quantitatively modifications. Considering high modifications degree, the polymer properties can change totally, when compared to the original ones. Some examples are the modification of polydienes through the introduction of polar groups into the polymer chain. Taking this into account it is possible to adjust some materials properties as oil and solvent resistance $^{[1]}$, reduction of gas permeability ${ }^{[2]}$, better adhesion to ceramics, metals and textiles ${ }^{[3,4]}$. Small modifications degree of polydiene and polyolefin showed significant changes considering the potential interaction with other polymers and fillers ${ }^{[5]}$. Moreover low modification degree can improve the compatibility of specific polymers, and also, due to the strong polymer-filler interaction, leads to changes in the dynamical-mechanical properties improving the wet-skid resistance ${ }^{[6]}$. The modification of analogous polymers has been used to link side chemical groups to the main chain in order to have, chemically bonded in the own chain, some groups, which can act as antioxidants ${ }^{[7]}$, curing agents ${ }^{[8]}$, as well as coupling agent to rubber-filler interaction ${ }^{[9]}$. The polyolefin modification is based on the double bonds reactivity. The most common and explored reactions are i.e. epoxidation, maleination, carboxilation, sulfonation and others ${ }^{[2,10-15]}$.

The elastomer reinforcement by using filler needs, generally, strong physical interactions between the segments of the polymer chain and the filler surface ${ }^{[16,17]}$. In some cases the reinforcement is supported by chemical bond of the polymer with the filler surface, by using coupling agent ${ }^{[18,19]}$.

This interaction can strongly affect the physical properties, as well as the dynamic-mechanical properties. The modulus of an unfilled compound practically has no change with the variation in the deformation amplitude, but this modulus decrease significantly to filled rubber compounds ${ }^{[20]}$. The non-linear dependency of $\mathrm{G}^{\prime}$ as a function of deformation amplitued (Payne effect) can be explained due to the breakdown of the filler network considering a continuous increase in the periodic deformation ${ }^{[21,22]}$. Through the improvement of the

Corresponding author: Tatiana L. A. C. Rocha, Instituto de Química, UFRGS, Av. Bento Gonçalves 9500, CEP: 91501-970, Porto Alegre, RS. E-mail: teythy@yahoo.com.br 
Table 1. Characteristics of the rubber employed in this study.

\begin{tabular}{lcccccc}
\hline Rubber & $\overline{\boldsymbol{M}} \boldsymbol{w}$ & $\overline{\boldsymbol{M}} \boldsymbol{n} / \overline{\boldsymbol{M}} \boldsymbol{w}$ & $\begin{array}{c}\text { Styrene } \\
(\mathbf{w t} \%)\end{array}$ & $\begin{array}{c}\text { Vinyl } \\
(\mathbf{w t} \%)\end{array}$ & $\begin{array}{c}\mathbf{1 , 4 - c i s} \\
(\mathbf{w t} \%)\end{array}$ & $\begin{array}{c}\mathbf{1 , 4 - t r a n s} \\
(\mathbf{w t} \%)\end{array}$ \\
\hline SBR-1 & 172650 & - & 25 & 8 & 67 & \\
SBR-2 & 206600 & 2.12 & 25 & 25 & 50 & 25 \\
SBR-3 & 188600 & - & 25 & 50 & 24 & 51 \\
SBR-4 & 212400 & 1.20 & 25 & 10 & 40 & 50 \\
BR-1 & 137000 & 1.08 & - & & & \\
\hline
\end{tabular}

polymer-filler interaction and filler dispersion, the dependency of the modulus as a function of variation in deformation amplitude becomes to be less pronounced.

The goal of the present work is to emphasize the influence of polydiene epoxidation on the interaction between polymeric matrix and precipitated silica, considering mainly the dynamic-mechanical properties in the glass temperature region and taking into account the dependency of the deformation amplitude at room temperature.

\section{Experimental}

\section{Material}

All rubbers used in this work were obtained by anionic polymerization. The rubber characteristics information are described in Table 1.

\section{Epoxidation}

To obtain epoxidized rubbers the reaction was carried out as described in the literature to SBR and BR rubber ${ }^{[13-15]}$, where a mixture of hydrogen peroxide and formic acid was used to generate the peracid in situ, which is responsible to the epoxidation of the double bonds in the Elastomers.

Taking into account the rubbers identified in Table 1, a kinetic study was done in function of the epoxidation degree, which was varied from 7 to $75 \mathrm{~mol} \%$. The epoxidized rubbers studied in this work are identified through the abbreviation which indicates first the name of the rubber followed (in brackets) by the epoxidation degree, i.e. SBR-2(ep7), which is that this is a SBR type 2 with $7 \mathrm{mo} \%$ of double bonds epoxidized.

\section{Sample preparation}

The mixture of epoxidized rubber and filler, in this case commercial precipitated silica, VN3 (Degussa AG), was carried out in a internal mixer (Thermo Haake PolyLab System) fitted out with a chamber of $50 \mathrm{~mL}$. The silanization reaction, using TESPT (Si69) as coupling agent, was carried out in three stages, as described in the literature ${ }^{[23]}$. After the silanization this material was identified as VN3+Si69 in this work.

\section{Characterization}

The characterization of the epoxidized material was done as described and discussed in our previous work ${ }^{[15]}$, by using the FT-IR (infra red), ${ }^{1} \mathrm{H}-\mathrm{NMR}$ (magnetic nuclear resonance) e DSC (differential scanning calorimetry).

After mixtures, samples were vulcanized in a torque rheometer at $160{ }^{\circ} \mathrm{C}$ to obtain the optimum time of cure and after that the vulcanization process was done in a press using $\mathrm{S} / \mathrm{CBS}-1,6 / 2,5 \mathrm{phr}$ as cure system.

The dynamic-mechanical properties of the vulcanized rubbers were analyzed considering the torsion modulus in an equipment Ares 3A5 Rheometric Scientific, considering a sweep temperature measurement $\left(-100\right.$ till $\left.+100{ }^{\circ} \mathrm{C}\right)$, a heating rate of $1{ }^{\circ} \mathrm{C} / \mathrm{min}$, frequency of $1 \mathrm{~Hz}$ and deformation amplitude of $1 \%$. It was determined the dependency of the loss and storage modulus in function of amplitude, using samples with double sandwich geometry considering shear modulus in an Elastomer-Testing-System (831.50 MTS Systems Corp) at room temperature $\left(23{ }^{\circ} \mathrm{C}\right)$, considering the force region between $2 \mathrm{~N}$ and $5 \mathrm{Kn}$.

\section{Results e Discussion}

\section{Thermal Analysis}

The characterization of thermal behavior of the material was focused on the glass tranbsition temperature. A summary of the results is showed in Figure 1.

The non modified rubbers showed an increase in the $\mathrm{Tg}$ values, which is dependent on the increase of the styrene content and specially in the vynil units. Due to the presence of this side groups, the cross section of the chain increases and at the same time the mobility of the chain is diminished reflecting a change in the values of $\mathrm{Tg}$.

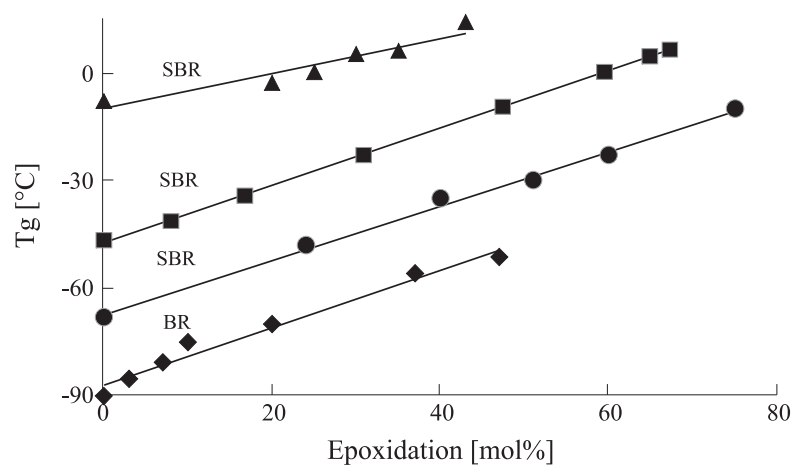

Figure 1. Influence of the epoxidation degree on $\mathrm{Tg}$ of epoxidized rubbers 
The higher reactivity of the butadiene -1,4-cis and -1,4trans units allows that the epoxidation reaction initiates first a modification into the main chain of the rubber and do not reacting with the vynil units. A statistical distribution of the epoxy groups results finally in a linear increase of the $\mathrm{Tg}$ as the epoxidation degree becomes higher. This result can be understanding by the reduction of the free energy translacional and rotational of the modified units, which is caused by the increase in the inter- and intramolecular interaction of the epoxy groups.

To BR as well as all kind of SBR studied (except SBR-3), the epoxidation effect results in the same increment on the increase of Tg, ca. $0,75 \mathrm{~mol} \%$ of epoxy groups. This similarity in the thermal behavior indicates that there is a statistical reposition of double bonds by the epoxy groups in detriment to formation of small blocks of epoxidized segments. As consequence of that, there is an similar increase on the characteristic relaxation time of the rubber chain.

\section{Dynamic-Mechanical Properties}

\section{Dependency of G' as variation of amplitude}

The influence of the epoxidation in the main chain of SBR can be better understanding through the linear viscoelastic behavior of filled compounds. This normally reflect the state of the filler network and the breakdown of this network is induced by the increase in the amplitude of deformation during the dynamic-mechanical experiment.

A vulcanized sample, obtained from a reference mixture, contained mainly SBR-2 non epoxidized and precipitated silica, presents a value of the storage modulus $\left(G^{\prime}\right)$ at low amplitude of deformation, which is 4 times higher than that value showed by a mixture of SBR-2(ep7)/silica. This reduction of $\mathrm{G}$ ' shows a slightly network, due to the favorable energetically interaction between epoxy groups of the epoxidized rubber and the silanol groups present onto the silica surface. Because of that, it is possible to have a better dispersion leading to a reduction of the Payne effect (Figure 2).

The modification of the silica surface activity is obtained via silanization in situ, which has been used to reduce the silica polarity. As expected, it was observed a reduction in the $\mathrm{G}^{\prime}$ and in the Payne effect as the silanization takes place in the

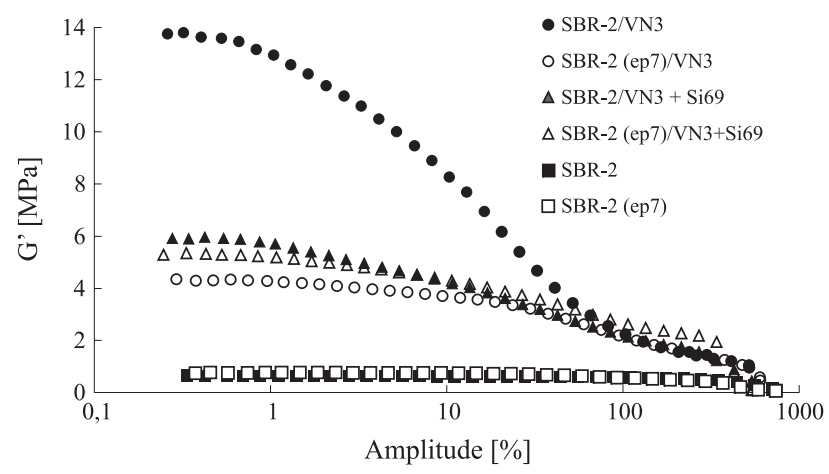

Figure 2. Influence of silica modification on the interaction elastomer-filler of SBR-2 and SBR-2(ep7). precipitated silica. Analyzing the dependency of $\mathrm{G}^{\prime}$ as function of deformation amplitude to the compound SBR-2/silica/ silane, it can be seen that the silanization leads to a decrease of 2.5 ties of the G'value in comparison to the reference compound. However, it should be noticed that first, the reduction of the Payne effect is remarkably lower than that obtained to the SBR-2(ep7) and non silanized silica compound and, second, the value of $\mathrm{G}^{\prime}$ obtained to SBR2(ep7) and silanized silica is comparable to the SBR-2/sílica/ silano system.

Taking into account the vulcanized SBR-2(ep7), the in situ silanization of the precipitated silica leads to a small increase in the $G^{\prime}$ values, indicating that the polymer-filler interaction is masked by the modification of the silica surface activity. As the silica surface becomes partially hydrophobic by the in situ silanization, the epoxy groups, which are polar, can not interact anymore which the same intensity as they do with the non silanized silica. Taking this into account the filler-filler interaction becomes to be stronger and $\mathrm{G}^{\prime}$ is higher. Based on that, the idea, that $\mathrm{G}^{\prime}$ is very sensitive to changes in the polymer-filler interaction and can be caused either by the functional groups of the polymer or by modification in the filler surface activity, becomes more pronounced. The study of the influence of the epoxidation on the dynamic-mechanical behavior of SBR blends, original and epoxidized, is presented in Figure 3.

It is important to see, that as the content of SBR-2(ep7) is increased in blends, the G'value decrease remarkably. Only
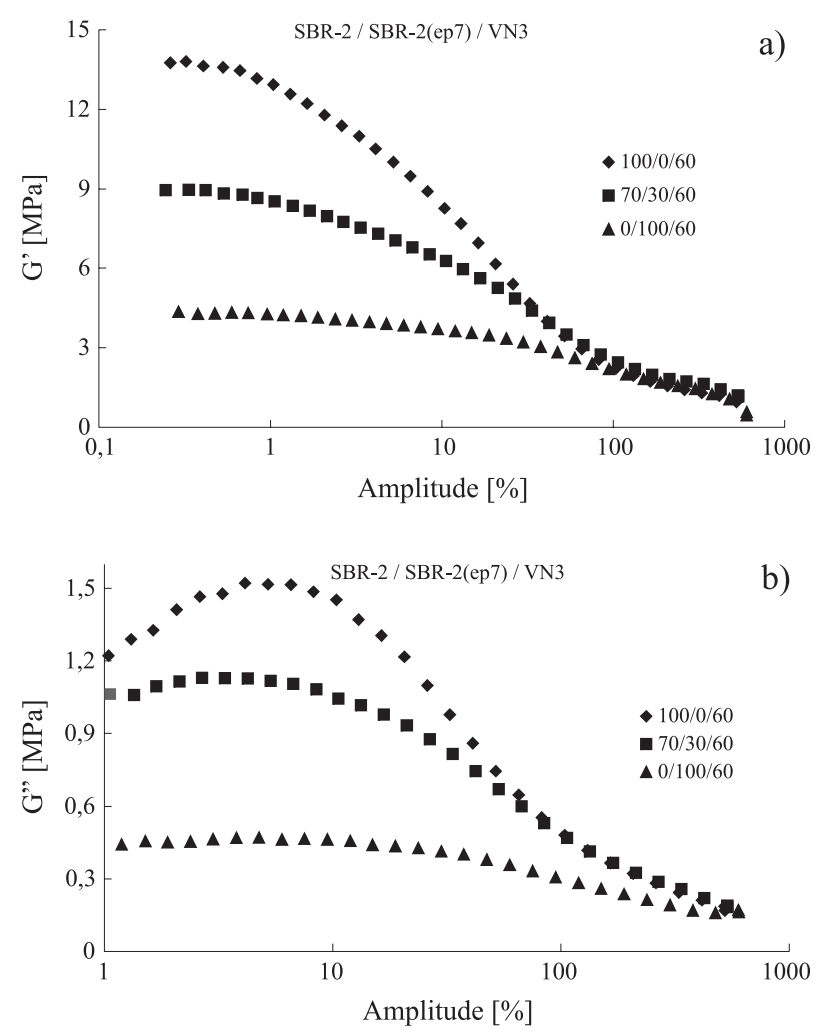

Figure 3. Influence of the epoxidized rubber content on a) storage modulus and b) loss modulus, considering a rubber compound filled with $60 \mathrm{phr}$ of silica. 


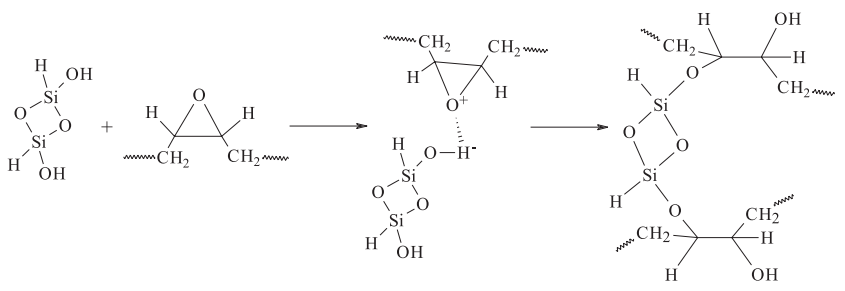

Figure 4. Schema of a proposed mechanism for the epoxidized rubbersilica interaction.

30 parts (weight) of SBR-2(ep7) in blends, which is similar to $2 \mathrm{~mol} \%$ of epoxy groups in the total of the blend, leads to a decrease of $40 \%$ in the $\mathrm{G}^{\prime}$ value. Considering the broad amplitude region of deformation, it can be seen a very small increase in the $\mathrm{G}^{\prime}$ value, as the epoxidation content increase. Analysing the loss modulus, G", it was observed a decrease about $35 \%$ of the maximum value of this modulus, as the content of SBR-2(ep7) increases, confirming the idea of a more efficient rubber-filler interaction (Figure $3 b$ ).

The relatively strong interaction, which occurs between epoxidized SBR and precipitated silica, can be attributed to formation of hydrogen bonds or even chemical bonds formed after a possible ring opening (epoxy group) and covalent bond. An proposed schema of this mechanism is presented in Figure 4.

\section{Rubber-filler interaction (glass transition region)}

This part of the work discuss the influence of the silica precipitated presence in blends on the $\mathrm{G}^{\prime}$ and $\mathrm{G}$ " moduli for epoxidized and non epoxidized SBR, considering a sweep temperature experiment at amplitude of deformation and frequency constant.

It is already ready known that important information about the rubber-filler interaction can be obtained from the analysis of the loss modulus of a filled compound in the glass transition region as a function of temperature ${ }^{[24]}$. The area of the maximum peak of the loss modulus indicates the dissipated energy by volume unit of a sample during the transition from the glass region (rigid) to the flexible stage. If the rubberfiller interactions are present a polymer system, a fraction of the polymer chain is immobilized in the interface rubber-filler. Therefore the dissipated energy during the glass transition increase above the level of the sample withouth filler, due to the contribution of the fixed polymeric chain. For this increase there are two main contribution, the volume fraction of the immobilized polymeric layer and the rubber-filler interaction. Consequently, monitoring the increase of the amplitude (or area) of the maximum in G" in the glass transition, qualitative information about the rubber-filler interaction can be deduced.

The changes in the G" caused by the incorporation of $60 \mathrm{phr}$ of silica in SBR and SBR-2(ep7), respectively, becomes to be evident when the values are compared with those of the vulcanized without filler (Figure 5).

Considering the system without filler, even $7 \mathrm{~mol} \%$ of epoxy groups in the main chain lead to considerable variation in the Tg and maximum value of G". This result underlines the thermo-analytical variations considering dynamic changes in the chains (see Figure 1).

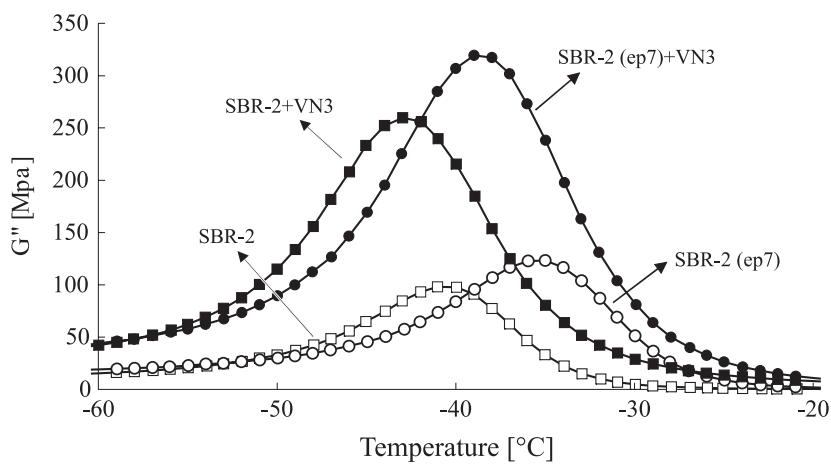

Figure 5. Interaction analysis between rubber matrix, SBR-2 e SBR-2(ep7), filled with $60 \mathrm{phr}$ of silica (VN3) considering the loss modulus $60 \mathrm{phr}$ variation in a sweep temperature experiment at constant amplitude deformation $(0,1 \%)$.

The incorporation of precipitated silica in both polymers leads to small changes in the glass transition temperature and, at the same time, causes remarkably increase of the maximum G" value. A more detailed date evaluation shows that by the relative increase of the G" maximum is more pronounced to SBR-2(ep7)/silica than to SBR/silica, if the unfilled compound is taking as reference. Considering that the effect of hydrodynamic reinforcement act in the same manner in both systems, it is possible to say that this higher maximum G" value for SBR-2/silica occurs due to the specific interaction rubber-filler.

Another point is achieved by comparing the dynamicmechanical effects caused by the use of silanized and non silanized silica (Figure 6).

Considering the same filler content, the compound with silanized silica presents a maximum G" value lower (70MPa) than that with non silinized silica. This result can be understanding, in the case when the silica surface activity decrease, due to the silanization reaction. As consequence of the silanization, the physical interaction of the less polar filler surface with epoxidized SBR, or the cross section of the chemical bond became reduced. Both mechanisms cause a decrease in the volume fraction of the polymeric chain strongly immobilized onto the filler surface. Therefore less mechanical energy is dissipated during the glass transition process for systems containing silanized silica.

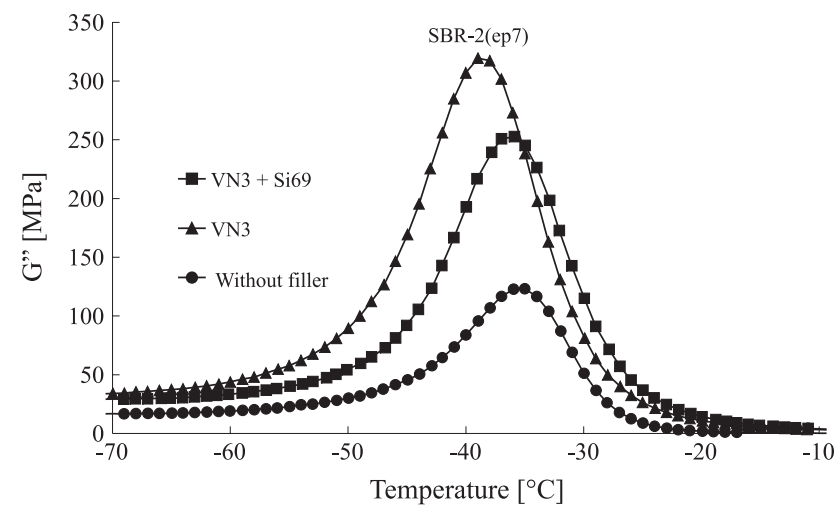

Figure 6. Influence of the silica polarity on the rubber-filler interaction of an elastomer with $7 \mathrm{~mol} \%$ of epoxy groups -SBR-2(ep7)- 


\section{Conclusion}

The $\mathrm{Tg}^{\text {'s }} \mathrm{s}$ of SBR and BR are increased the higher the epoxidation content. As the polymeric chains became epoxidized theer ist a strong interaction between them leading to a decrease in the mobility of the chain.

The strong interaction between silica and epoxidized rubber occurs due to the pronounced polar character of the epoxidized rubber.

Small quantities of SBR with only $7 \mathrm{~mol} \%$ of epoxy groups are enough to reduce the $G$ ' value around four times, indicating a remarkable improvement in the rubber-filler interaction.

\section{Acknowledgments}

The authors wish to thank the Conselho Nacional de Pesquisa (CNPq), Coordenação de Aperfeiçoamento de Pessoal (CAPES) and Deutscher Akademischer Austauschdiente (DAAD) for the financial support and Bayer AG and Degussa AG for the material support during this study.

\section{References}

1. Roy, S.; Gupta, B. R. \& De, S. K. - Elastomer Technology Handbook; editado por Cheremisinoff, N. P. (1993)

2. Baker, C. S. L.; Gelling, I. R. \& Newell, R. - Rubber Chem. Technol., 58, p.67 (1985).

3. Wang, X.; Zhang, H.; Wang, Z. \& Jiang, B. - Polymer, 38, p.5407 (1997).

4. Gnecco, S.; Pooley, A. \& Krause, M.- Polymer, 37, p. 609 (1996).

5. Bhowmick,A. K. \& Stephens,H. L. - "Handbook of Elastomers", Dekker, New York (2001)

6. Comander, R. - Global Rubber 2000 Sarnia (Canadá).

7. Margaritis, A.G. \& Kalfoglou, N.K. - Polym.J., 24, p.1043(1988).

8. Nuyken, O.; Wedner, R. \& Schuster, R. H. - Makromol. Chem., 190, p.459(1989).
9. Hofstetter, J., Tese de Doutorado, University of Strassbourg (1997).

10. Sheng, J.; Lu, X. L. \& Yao, K. D. - J. Macromol. Sci.Chem., A27(2), p.167 (1990).

11. Mokrini, A. \& Acosta, J. L. - Polymer, 42 p.9 (2001).

12. Badran, B. M.; El-Souckary, M. H. \& Aggour, Sh. Elastomerics, April, p.40 (1980).

13. Jacobi, M. M.; Rocha, T. L. A. C; Schuster, R. H.; Neto, C. P. \& Schneider, C. G. - Kautsch. Gummi Kunstst., 55(11), p.590 (2002).

14. Jacobi, M. M.; Santin,C. K.; Vigânico, M. E. \& Schuster, R. H. - Kautsch. Gummi Kunstst. 57(3), p.82 (2004).

15. Rocha, T. L. A. C.; Jacobi, M. M. e Schuster, R. H. Polímeros: Ciência e Tecnologia, 14(5) p.377 (2004).

16. Kraus, G. "Reinforcement of Elastomers, WileyInterscience, New York (1965).

17. Donnet, J.-B.; Bansal \& M.-J. Wang (Eds.), "Carbon Black Science and Technology", Marcel Dekker Inc. New York (1993).

18. Görl, U.; Hunsche, A.; Müller, A. \& Koban, H. G. - Rubber Chem. Technol., 70, p.608 (1997).

19. Fröhlich, J. \& Lugisland, H. D. - Rubber World, 28, p.244 (2001)

20. Payne, A. R. J. - Polym. Sci., 6, p.57 (1962).

21. Medalia, A. I. - Rubber Chem. Technol., 59, p.432 (1986).

22. Wang, M.-J. - Rubber Chem. Technol., 72, p.430 (1999).

23. Rocha, T. L. A. C. - "Influência da Modificação Química de Polidienos sobre suas Propriedades Finais", Tese de Doutorado, Universidade Federal do Rio Grande do Sul, Brasil (2003).

24. Ziegler, J. \& Schuster, R.H. - Kautsch. Gummi Kunstst. 56(4), p.159 (2003).

Enviado: 29/08/05

Reenviado: 26/01/06

Aprovado: 07/02/06 